\title{
Protective effects of VEGF treatment on focal cerebral ischemia in rats
}

\author{
AIMEI ZHANG, LUNAN LIANG, HUANFU NIU, PENG XU and YONGNAN HAO \\ The Affiliated Hospital of Jining Medical College, Jining, Shandong 272029, P.R. China
}

Received March 14, 2012; Accepted July 25, 2012

DOI: $10.3892 / \mathrm{mmr} .2012 .1069$

\begin{abstract}
The aim of this study was to determine the effects of VEGF treatment on focal cerebral ischemia in rats. Rats were administered PBS or VEGF at concentrations of 10, 20 or $30 \mu \mathrm{g} / \mathrm{ml}$. The effects of VEGF on the rat infarct volume and neurological deficits were investigated. Transmission electron microscopy was used to observe the ultrastructure of the cerebral cortex. Treatments with VEGF reduced the infarct volume and improved neurological functions. VEGF increased microvessel generation and also inhibited apoptosis in the cerebral cortex and basal ganglia. For the rats in the $30 \mu \mathrm{g} / \mathrm{ml}$ VEGF group, an even higher number of proliferative endothelial cells were observed by electron microscopy. In conclusion, VEGF treatment has protective effects on focal cerebral ischemia in rats.
\end{abstract}

\section{Introduction}

Ischemic cerebrovascular diseases are a common type of aggressive disease with high rates of incidence, mortality and morbidity. Therefore, studies on the pathophysiology of these diseases and new treatment strategies are necessary, since there are currently no effective clinical treatments. For example, the factors that promote angiogenesis might be helpful for the recovery of patients with cerebral ischemia.

VEGF plays a significant role in the increase of vascular permeability $(1,2)$. In the brain, VEGF is considered the main medium of peritumoral vasogenic brain edema $(3,4)$. Animal and clinical experiments have shown that shortly after focal cerebral ischemia, leakage in the vascular permeability barrier occurs, leading to cerebral edema. VEGF expression peaks when vasogenic brain edema following ischemia is most severe, so the high VEGF expression may be associated with blood-brain barrier leakage. It has already been suggested in previous studies that in patients with cerebral ischemia, the microvascular density of the ischemic hemisphere increased

Correspondence to: Professor Lunan Liang, The Affiliated Hospital of Jining Medical College, 79 Guhuai Road, Jining, Shandong 272029, P.R. China

E-mail: lianglunan@yahoo.cn

Key words: cerebral ischemia, vascular endothelial growth factor, apoptosis significantly when compared with contralateral lesions, and the number of microvessels in the penumbra area may be correlated with the survival time of the stroke patients (5-7).

Results showed that following persistent cerebral ischemia in rats, local injection of VEGF in the cerebral cortex promoted angiogenesis 7 days following ischemia. The treatment group of $30 \mu \mathrm{g} / \mathrm{ml} \mathrm{VEGF} \mathrm{showed} \mathrm{the} \mathrm{most} \mathrm{significant} \mathrm{effect} \mathrm{and} \mathrm{the}$ group of $10 \mu \mathrm{g} / \mathrm{ml}$ showed the least significant effect, which indicated that the effect of angiogenesis may be related to the concentration of VEGF. Within a certain range, the higher the dose, the greater the effect.

In this study, the effects of exogenous VEGF on the infarct volume of cerebral ischemia, neurological deficits, cerebral edema, microvascular density and apoptosis were investigated. Electron microscopy of vascular endothelial cells and apoptotic cell ultrastructure were performed to study whether excessive proliferation causes formation of the vascular tumorlike structures. The protective roles of VEGF suggest that exogenous VEGF may be appropriate for clinical use.

\section{Materials and methods}

Animals. Forty healthy male Wistar rats 3-4 months old, each weighing 250-300 g, were provided by the Experimental Animal Center of Shandong Medical University (China). The rats were randomly divided into 4 groups, administered PBS and 10,20 or $30 \mu \mathrm{g} / \mathrm{ml}$ of VEGF. The PBS group served as the control. The infarct volume ratio and the neurological deficits were determined by MRI. Microvessel density, apoptosis in brain slices and brain edema were determined. The focal cerebral ischemia rat model was made using the middle cerebral artery occlusion (MCAO) method described by Longa et al (8). All animal experiments were conducted according to the animal experimental guidelines of Jining Medical College (Shandong, China). The study was approved by the ethics committee of Jining Medical College.

Drug treatments. VEGF was diluted to concentrations of 10 , 20 or $30 \mu \mathrm{g} / \mathrm{ml}$ using sterile $0.1 \mathrm{M}$ PBS containing $0.1 \%$ fetal calf serum. VEGF solutions were slowly injected into the left cerebral cortex of rats. For the control group, sterile $0.1 \mathrm{M}$ PBS containing $0.1 \%$ fetal calf serum was injected into the left cerebral cortex of the rats. Each rat was injected three times at 1,24 and $48 \mathrm{~h}$ after infarct. Observation was performed 7 days after infarction. 
Table I. Treatment of rats with different concentrations of VEGF.

\begin{tabular}{lcccr}
\hline & PBS & $10 \mu \mathrm{g} / \mathrm{ml}$ & $20 \mu \mathrm{g} / \mathrm{ml}$ & $30 \mu \mathrm{g} / \mathrm{ml}$ \\
\hline Nos. of rats & 7 & 8 & 8 & 9 \\
Infarct volume (\%) & $43.21 \pm 7.12$ & $37.26 \pm 5.81^{\mathrm{a}}$ & $33.62 \pm 8.24^{\mathrm{b}}$ & $27.64 \pm 6.77^{\mathrm{c}}$ \\
Neurological deficit scores & $2.86 \pm 0.69$ & $2.50 \pm 0.76^{\mathrm{a}}$ & $2.00 \pm 0.54^{\mathrm{b}}$ & $1.78 \pm 0.67^{\mathrm{c}}$ \\
\hline
\end{tabular}

${ }^{\mathrm{a}} \mathrm{P}>0.05,{ }^{\mathrm{b}} \mathrm{P}<0.05,{ }^{\mathrm{c}} \mathrm{P}<0.01$.

Neurological deficit score. The neurological deficit scores were calculated according to the 0-5 grade scoring criteria described by Longa et al (8), with the greater number indicating more severe function deficits.

Infarct volume ratio. The $1.5 \mathrm{~T}$ MRI machine was used to determine the anatomy structure of the rat brains, with the following parameters: 3 inches of surface coils, a large matrix (256x256), small view field (FOV, $8 \times 4 \mathrm{~cm}$ ), $3 \mathrm{~mm}$ of thickness and $0.3 \mathrm{~mm}$ of intervals. According to the location and extent of the abnormal signal area on each layer of the scanned image, the ratio of the infarct volume to the contralateral cerebral hemisphere was calculated.

Microvessel density. The immunohistochemical SP method was performed to detect microvessel density, using antibody against laminin concentration (1:200; Santa Cruz Biotechnology, Inc., USA). Ten high power microscopic fields (40x10) were randomly selected in the infarct cortex and basal ganglia in each slice. The number of positive vessels per field was calculated.

Apoptosis. The oligonucleotide terminal deoxynucleotidyl transferase-mediated dUTP nick-end labeling method (TUNEL) was used to detect in situ apoptosis. At 40x10 high power, 10 fields were randomly selected around the infarct cortex and basal ganglia in each slice. The number of total cells and positive cells were counted to calculate the positive cell rates.

Electron microscopy. Rat tissues were fixed in $4 \%$ glutaraldehyde and examined by electron microscopy. The brain tissue was rinsed with $2 \%$ glutaraldehyde and then fixed with $1 \% \mathrm{~S}_{4} \mathrm{O}_{4}$. Following acetone dehydration and the EPON-821 embedment, $1-\mu \mathrm{m}$ ultrathin sections were cut. With sodium acetate and citrate double staining, the ultrastructure of apoptotic cells, endothelial cell proliferation and deterioration tendency were observed by transmission electron microscopy.

Statistical analysis. Data were analyzed by SPSS software and given as the mean \pm SD. Single-factor analysis of variance, q-test and t-test were performed. $\mathrm{P}<0.05$ was considered to indicate statistically significant differences.

\section{Results}

$V E G F$ reduces infarct volume and improves neurological functions. To determine whether VEGF treatment affects

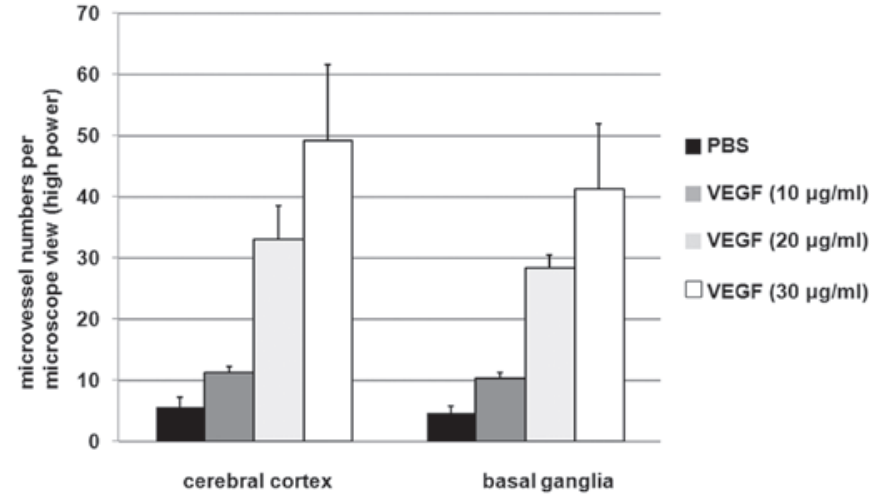

Figure 1. VEGF increases microvessel generation. The microvessel numbers in the cerebral cortex and basal ganglia were detected on Day 7 post-treatment. Rats were administered PBS or VEGF (10, 20 or $30 \mu \mathrm{g} / \mathrm{ml}$ VEGF).

focal cerebral ischemia in rats, rats were administered PBS or VEGF at concentrations of 10,20 or $30 \mu \mathrm{g} / \mathrm{ml}$. The effects of VEGF on rat infarct volume and neurological deficits were investigated as described in Materials and methods and the results are presented in Table I.

As shown in Table I, there were no significant differences in infarct volume and neurological deficit scores between the PBS and VEGF $(10 \mu \mathrm{g} / \mathrm{ml})$ group $(\mathrm{P}>0.05)$. However, when rats were treated with $20 \mu \mathrm{g} / \mathrm{ml} \mathrm{VEGF}$, infarct volume ratios and neurological deficit scores were both decreased when compared with the PBS group. When rats were treated with $30 \mu \mathrm{g} / \mathrm{ml} \mathrm{VEGF}$, the mean infarct volume ratio decreased to $27.64 \pm 6.77 \%$, while the mean infarct volume ratio of the PBS group was $43.21 \pm 7.12 \%$. The mean neurological deficit score of the $30 \mu \mathrm{g} / \mathrm{ml}$ VEGF group was $1.78 \pm 0.67$, whereas the mean score of the PBS group was $2.86 \pm 0.69$. These results suggest that treatments with VEGF reduce the infarct volume and improve neurological functions.

VEGF increases microvessel generation. To determine the effects of VEGF treatment on microvessel generation, the microvessel numbers in the cerebral cortex and basal ganglia of rats administered PBS or VEGF were detected. As shown in Fig. 1, treatments with 20 and $30 \mu \mathrm{g} / \mathrm{ml}$ VEGF significantly improved microvessel numbers compared with the PBS group. Treatment with $30 \mu \mathrm{g} / \mathrm{ml}$ VEGF increased microvessel numbers $\sim 10$-fold when compared with the PBS group, suggesting that VEGF increases microvessel generation.

VEGF inhibits apoptosis in the cerebral cortex and basal ganglia. To determine the effects of VEGF treatment on 
A

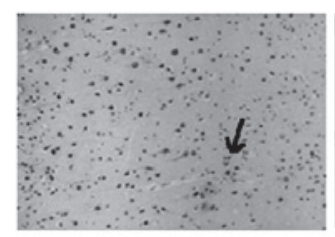

PBS

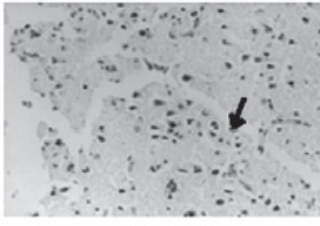

VEGF $(10 \mu \mathrm{g} / \mathrm{ml})$

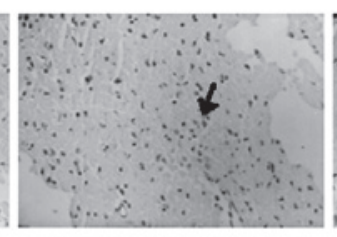

VEGF $(20 \mu \mathrm{g} / \mathrm{ml})$

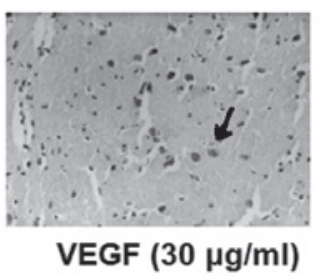

B

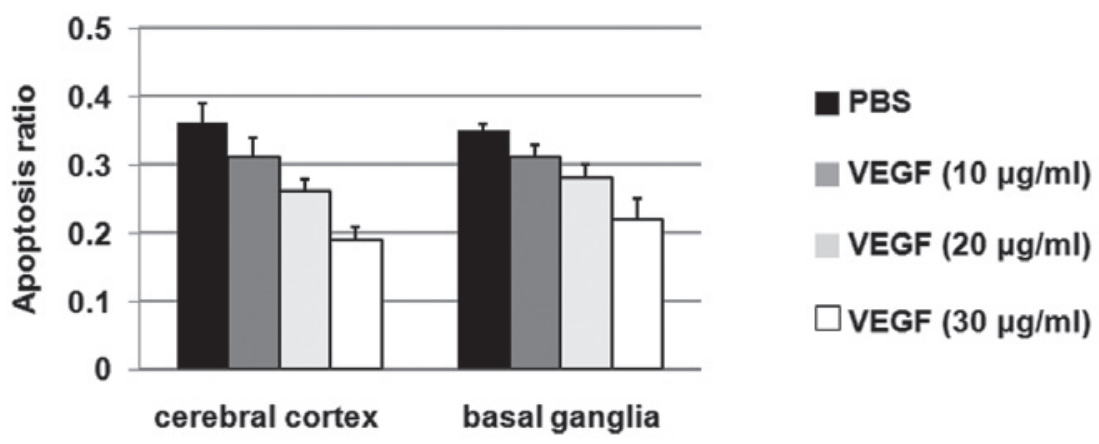

Figure 2. VEGF inhibits apoptosis in the cerebral cortex and basal ganglia. (A) The apoptotic cell numbers in the cerebral cortex and basal ganglia from rats administered PBS or VEGF $(10,20$ or $30 \mu \mathrm{g} / \mathrm{ml}$ ) were determined using the TUNEL method. Apoptotic cells are indicated with arrows. (B) The ratio of the apoptotic cell numbers to the total cell numbers from rats in each group was calculated and is presented here.

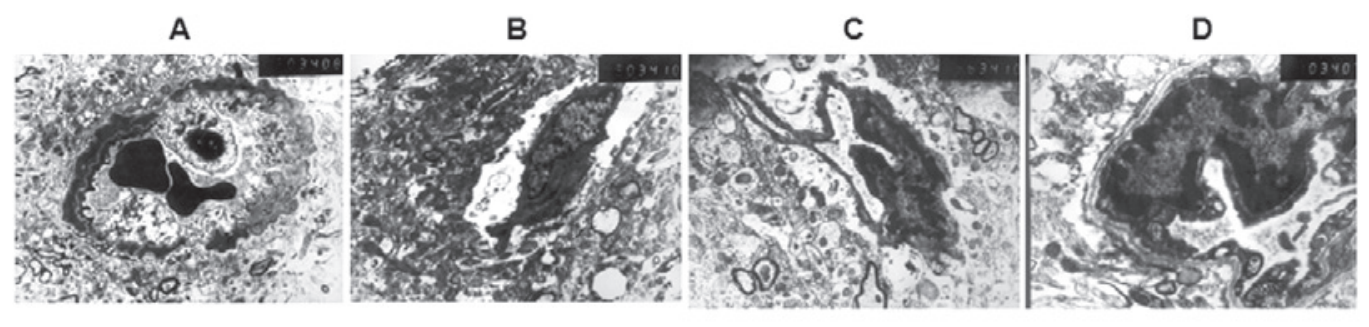

Figure 3. Electron microscopy of the vascular endothelium in the ischemic peripheral brain zone of rats treated with PBS or VEGF. The rats were injected with (A) PBS, (B) $10 \mu \mathrm{g} / \mathrm{ml} \mathrm{VEGF} \mathrm{(C)} 20 \mu \mathrm{g} / \mathrm{ml}$ and (D) $30 \mu \mathrm{g} / \mathrm{ml} \mathrm{VEGF.}$

apoptosis, the apoptotic cell numbers in the cerebral cortex and basal ganglia from rats administered PBS or VEGF (10, 20 or $30 \mu \mathrm{g} / \mathrm{ml}$ ) were determined using the TUNEL method. As shown in Fig. 2A, VEGF treatments with 20 and $30 \mu \mathrm{g} /$ ml VEGF significantly decreased apoptotic cell numbers when compared with the PBS group. The ratio of the apoptotic cell numbers to the total cell numbers from rats in each group was calculated and is shown in Fig. 2B. These results suggest that VEGF inhibits apoptosis in the cerebral cortex and basal ganglia.

VEGF improves growth of vascular endothelial cells. To determine the effects of VEGF on vascular endothelial cells, electron microscopy was performed to detect vascular endothelial cell changes in the ischemic peripheral brain zone of rats administered PBS or VEGF $(10,20$ or $30 \mu \mathrm{g} / \mathrm{ml})$. As shown in Fig. 3, for the rats in the PBS group, vascular endothelium was thin with partial necrosis and necrosis was observed in axons and dendrites. In rats administered $10 \mu \mathrm{g} / \mathrm{ml} \mathrm{VEGF}$, similar results were observed when compared with the PBS group. However, when the rats were administered VEGF at a concentration of $20 \mu \mathrm{g} / \mathrm{ml}$, more proliferative endothelial cells were observed and the rats in the $30 \mu \mathrm{g} / \mathrm{ml}$ VEGF group presented the most proliferative endothelial cells.

\section{Discussion}

In the present study we have shown that application of VEGF reduced apoptosis 7 days after ischemia. Infarct volume was reduced and neurological function was improved, which may be due to the effects of VEGF. Thus, VEGF may play a protective role. This effect is consistent with findings from previous studies. For example, it has been reported that VEGF stimulates axon growth and improves neuronal survival of mice on the neck and dorsal root ganglion (9). Also, VEGF has been found to promote the growth of cultured midbrain neurons $(10,11)$. Bilateral hippocampal ischemia test of rats indicated a direct protective effect of VEGF on neurons (12). Jin et al (13) found the neurotrophic effect of VGEF in studies of the mouse hippocampal HN33 cells (14).

The concentration and dosage of VEGF used in this experiment were based on previous VEGF experiments $(15,16)$. For 
example, Hayashi et al (15) applied VEGF on the surface of the cerebral cortex with similar concentrations. Zhang et al (16) applied intravenous infusion of $1 \mathrm{mg} / \mathrm{kg}$ VEGF165. In this study, slow and repeated injections were used due to the short half-life of the VEGF protein.

Previous studies focused on the effects of VEGF on angiogenesis following cerebral ischemia $(15,17)$, and in ventricle and brain parenchyma $(18,19)$. It has been demonstrated that the application of VEGF in the ventricle of non-ischemic adult rats would also promote angiogenesis (20), but it is generally accepted that VEGF would have a pro-angiogenic effect only after it binds to its specific receptor on endothelial cells $(21,22)$. The effect of VEGF on brain angiogenesis should be explored in future studies.

Cell death caused by ischemic brain damage may be caused by the same pathway $(23,24)$. Neuronal death following ischemia presents with forms of necrosis and apoptosis, related to active and passive cell death mechanisms, respectively (25-27). Activation of the apoptotic response may be an important step related to cell death, thus apoptosis may affect the final infarct volume (28). The inhibition of apoptosis and the reduction of ischemic penumbra would be effective in treating ischemic vascular diseases.

\section{References}

1. Chen XL, Nam JO, Jean C, et al: VEGF-induced vascular permeability is mediated by FAK. Dev Cell 22: 146-157, 2012.

2. Weis SM: Evaluation of VEGF-induced vascular permeability in mice. Methods Mol Biol 763: 403-415, 2011.

3. Nassehi D, Dyrbye H, Andresen M, Thomsen C, Juhler M, Laursen $\mathrm{H}$ and Broholm $\mathrm{H}$ : Vascular endothelial growth factor A protein level and gene expression in intracranial meningiomas with brain edema. APMIS 119: 831-843, 2011.

4. Schmid S, Aboul-Enein F, Pfisterer W, Birkner T, Stadek C and Knosp E: Vascular endothelial growth factor: the major factor for tumor neovascularization and edema formation in meningioma patients. Neurosurgery 67: 1703-1708, 2010.

5. Krupinski J, Kaluza J, Kumar P, Kumar S and Wang JM: Role of angiogenesis in patients with cerebral ischemic stroke. Stroke 25: 1794-1798, 1994.

6. Zan LK, Song YJ, Teng GX, et al: Expression and function of vascular endothelial growth factor and angiopoietins in rat brain after cerebral ischemia. Chin J Pathol 40: 834-839, 2011 (In Chinese).

7. Ma Y, Qu Y and Fei Z: Vascular endothelial growth factor in cerebral ischemia. J Neurosci Res 89: 969-978, 2011.

8. Longa EZ, Weinstein PR, Carlson S and Cummins R: Reversible middle cerebral artery occlusion without craniectomy in rats. Stroke 20: 84-91, 1989.

9. Sondell M, Lundborg G and Kanje M: Vascular endothelial growth factor has neurotrophic activity and stimulates axonal outgrowth, enhancing cell survival and Schwann cell proliferation in the peripheral nervous systerm. J Neurosci 19: 5731-5740, 1999.

10. Silverman WF, Krum JM, Mani N and Rosenstein JM: Vascular, glial and neuronal effects of vascular endothelial growth factor in mesencephalic explant cultures. Neuroscience 90: 1529-1541, 1999.
11. Ku DD, Zaleski JK, Liu S and Brock TA: VEGF induces EDRFdependent relaxation in coronary arteries. Am J Physiol 265: H586-H592, 1993.

12. Marti HJ, Bernaudin M, Bellail A, Schoch H, Euler M, Petit E and Risau W: Hypoxia-induced vascular endothelial growth factor expression precedes neovascularization after cerebral ischemia. Am J Pathol 156: 965-976, 2000.

13. Jin KL, Mao XO and Greenberg DA: Vascular endothelial growth factor: director neuroprotective effect in in vitro ishemia. Proc Natl Acad Sci USA 97: 10242-10247, 2000.

14. Jin KL, Mao XO, Nagayama T, Goldsmith PC and Greenberg DA: Induction of vascular endothelial growth factor receptors and phosphatidylinositol 3'-kinase/Akt signaling by global cerebral ischemia in the rat. Neuroscience 100: 713-717, 2000.

15. Hayashi T, Abe K and Itoyama Y: Reduction of ischemic damage by application of vascular endothelial growth factor in rat brain after transient ischemia. J Cereb Blood Flow Metab 18: 887-895, 1998.

16. Zhang ZG, Zhang L, Jiang Q, et al: VEGF enhances angiogenesis and promotes blood-brain barrier leakage in the ischemic brain. J Clin Invest 106: 829-838, 2000.

17. Mayhan W: VEGF increases permeability of the blood-brain barrier via a nitric oxide synthase/CGMP-dependent pathway. Am J Physiol 276: C1148-C1153, 1999.

18. Rosenstein JM, Mani N, Silverman WF and Krum JM: Patterns of brain angiogenesis after vascular endothelial growth factor administration in vitro and in vivo. Proc Natl Acad Sci USA 95: 7086-7091, 1998

19. Proescholdt MA, Heiss JD, Walbridge S, Mühlhauser J, Capogrossi MC, Oldfield EH, Merrill MJ: VEGF modulates vascular permeability and inflammation in rat brain. J Neuropathol Exp Neurol 58: 613-627, 1999.

20. Harrigan MR, Ennis SR, Masada T and Keep RF: Intraventricular infusion of VEGF promotes cerebral angiogenesis with minimal brain edema. Neurosurgery 50: 589-598, 2002.

21. Plate KH, Breier G, Millauer B, Ullrich A and Risau W: Up-regulation of vascular endothelial growth factor and its cognate receptors in a rat glioma model of tumor angiogenesis. Cancer Res 53: 5822-5827, 1993.

22. Plate KH, Breier G, Weich HA, Mennel HD and Risau W: VEGF and glioma angiogenesis: Coordinate induction of VEGF receptors, distribution of VEGF protein and possible in vivo regulatory mechanisms. Int J Cancer 59: 520-529, 1994.

23. Furlan M, Marchal G, Viader F, Derlon JM and Baron JC: Spontaneous neurological recovery after stroke and the fate of the ischemic penumbra. Ann Neurol 40: 216-226, 1996.

24. Rosenblum WI: Histopathologic clues to the pathways of neuronal death following ischemia/hypoxia. J Neurotrauma 14: 313-326, 1997.

25. Pulera MR, Adams LM, Liu H, et al: Apoptosis in a neonatal rat model of cerebral hypoxia ischemia. Stroke 29: 2622-2630, 1998.

26. Beiharz EJ, Williams CE, Dragunow M, et al: Mechanisms of delayed cell death following hypoxic-ischemic injury in the immature rat: evidence for apoptosis during selective neuronal loss. Brain Res Mol Brain Res 29: 1-14, 1995.

27. Sei Y, Von Lubitz KJ, Basile AS, Borner MM, Lin RC, Skolnick P and Fossom LH: Internucleosomal DNA fragmentation in gerbil hippocampus following forebrain ischemia. Neurosci Lett 171: 179-182, 1994.

28. Linnik MD, Miller JA, Sprinkle-Cavallo J, Mason PJ, Thompson FY, Montgomery LR and Schroeder KK: Apoptotic DNA fragmentation in the rat cerebral cortex induced by permanent middle cerebral artery occlusion. Brain Res Mol Brain Res 32: 116-124, 1995. 